\title{
Implication of Behavioral Finance in Investment Decision-making Process
}

\author{
${ }^{*}$ Agha Jahanzeb, Saqib Muneer, Saif-ur-Rehman \\ Faculty of Management and Human Resource Development (FPPSM) \\ University Technology Malaysia, Malaysia \\ *jahanzebdotcom@gmail.com
}

\begin{abstract}
Behavioral finance is a structure that supplements some parts of standard finance and replaces other parts. It portrays the behavior of investors and management in decision-making; it illustrates the outcomes of interactions between investors and managers in financial and capital markets. As decisionmaking is an art to undertake complex situations and investors make irrational decisions during their investments. Therefore, it is a unique art to choose a certain alternative from various alternatives available. Although behavioral finance does not claim that every investor would suffer from similar illusion, instead it sheds light on to take necessary initiatives to avoid such illusions, which influence the process of decision-making, particularly while making investments.
\end{abstract}

Keywords: Behavioral finance, decision-making, prospect theory, cognitive illusions

\section{Introduction}

Decision-making is an art to tackle complex situations. It is a cognitive process to choose an alternate among several possible alternative scenarios. One cannot make a decision by simply relying on his/her personal resources. The result can be a vision or an action of choice. Decision-making without certain planning can be fair but it might not end well. A manager's mental approach mediates the different problems occurring in different steps by analyzing them. Decision-making basically is a unique art to choose a certain alternative from various alternatives available. Moreover we can say that it is a process that is being followed by the alternatives that are thoroughly inspected and evaluated. Managers who want to compete in a challenging business environment must update themselves in many fields so that they can get desired results. It is important to understand that in present competitive global perspective investors must obtain capability to get best results out of their investments. In addition to this, investors should develop persistence and positive vision. Investors differ from one another in different aspects and demographic factors, i-e; socio-economic, education, sex, race and age. Few believe in more risk more return which is usually risky, whereas others believe in less risk less return which is always safe.

Hence the difficult part to play while making decision is to select the particular area and field of investment. Significant consideration is given to the best investment decision. Investors while constructing their investment portfolio need to consider their risk tolerance, rate of return, market conditions and other constraints. Behavioral Finance illustrates how different investors comprehend and react to the information available in the market. It is not necessary that all the investors always behave rationally or they predict quantitative models in same and unbiased manner. That is why Behavioral Finance gives significance to the behavior of invertors leading to several market anomalies. In present days, Behavioral Finance has become the constitutional part of the process of decision-making because its impacts influence the performance of the investors. Behavioral Finance helps investors to choose better financial decision and to avoid same high-priced mistakes in future. Ross, Westerfield \& Jaffe (2004), has divided risk into two main categories. According to him upward and downward movements by securities in markets (Beta coefficient) lie in first category. On the other hand, the second category is about the nonmarket risk which depends on the luck of a company and its concerned industry. According to the Prospect Theory of Tversky \& Kahneman (1979) the decisions made by decision-makers differ from the presumptions of economists, which they proved with the help of various experiments. Kahneman \& Tversky (1979) illustrated that the investors usually try to avoid taking risk when they are gaining, however they might choose to take risk when they are with losing stocks. Having precise argument about this analytical study is how to eliminate or minimize the cognitive and psychological biases in the process of investment decision making.

\section{Behavioral Finance and its Emergence}

Simon (1955, 1959), Margolis (1958) and Cyert \& March (1963) are among the early authors to comprise results related to psychology into corporate finance. Making money is the principal motive of an investor. 
During several past years, investments usually based on forecasting, performance, market timing. That used to produce ordinary findings. Huge gap between the returns available and the return received forced the investors to look into the matter and find the reasons. So, the fundamental mistakes during the process of decision-making were identified. In other words, we can say that investors make irrational decisions during their investments and psychological impact was found during these mistakes. Thus the Subject of Behavioral Finance which got popularity in the world of investment decisions and stock markets is not new as the researchers began to work on this field several years ago. Since many years, investors have been considering psychology an important factor while determining the market behavior, but formal studies have only been conducted in recent years in this field of behavioral finance (Muneer \& Rehman, 2012). Seminal role has been played by the paper of Slovic, (1972) regarding the misconceptions of an individual about risk and Kahneman \& Tversky (1979) papers on heuristic rule biases and the frames of decision. The findings of those studies were not in accord with rational traditional finance \& economic theory. Although there exist various definitions of Behavioral Finance but still a level of significance can be found. Lintner, (1998) explains about the definition of Behavioral Finance as 'the study of how humans interpret and act on information to make informed investment decisions' whereas Olsen, (1998) affirms that behavioral finance doesn't explain the rational behavior or points out a decision faulty, rather attempts to comprehend and forecast financial markets systematically. The important point to be noted here is that, no significant theory of Behavioral Finance exists.

\section{Implications and Principles of Behavioral Finance}

What traditional financial theory says is that, the decisions made by the investors are usually rational. Whereas the modern theories suggest that no such considerations compel the decision-makers. Most of the time, decisions of investors are inconsistent, or in others words we can say that cognitive illusions play a vital role to divert the human decisions, which have been categorized into two as shown in the figure below:

Figure 01: Cognitive Illusions

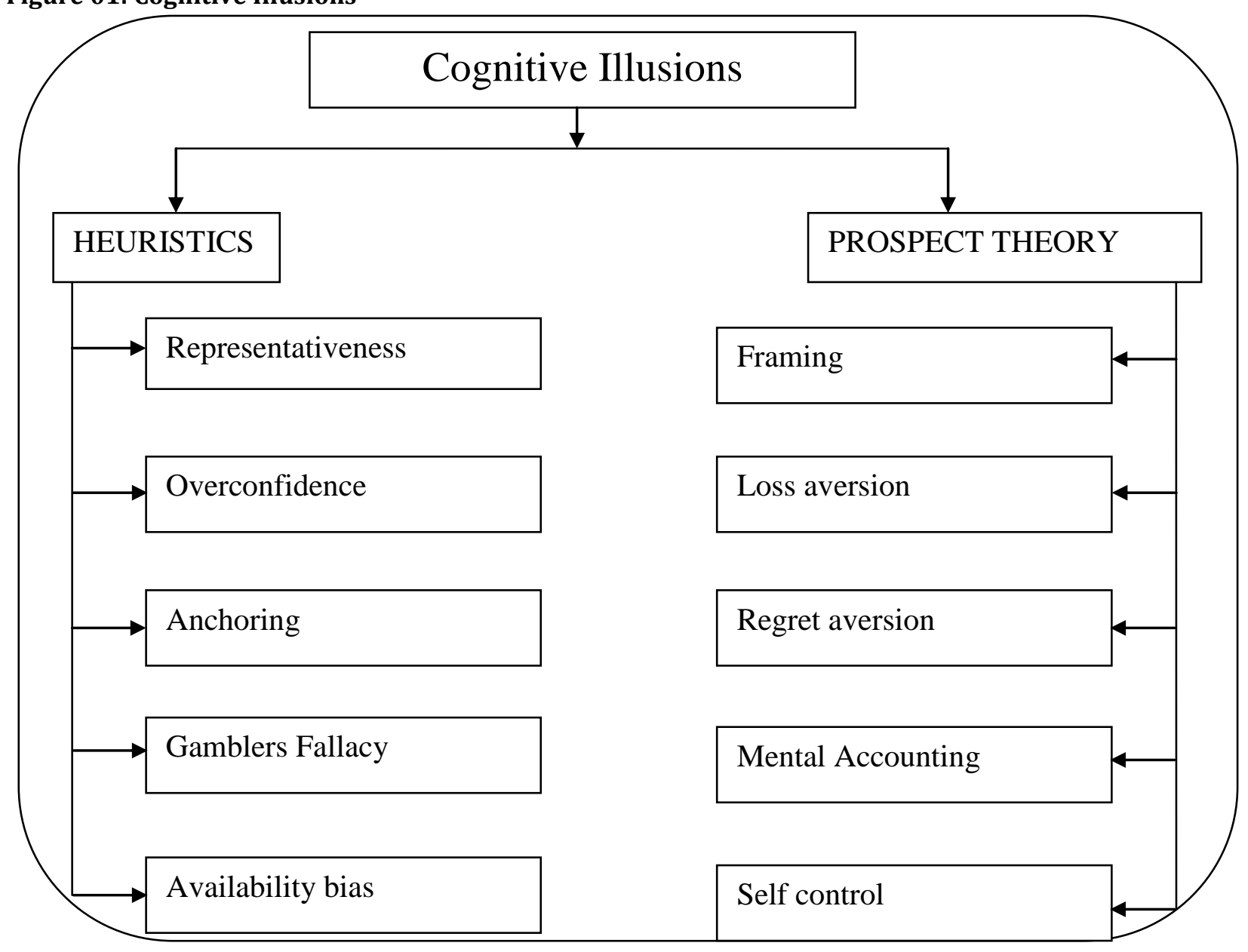

Source: construct by authors 


\section{Heuristic Decision Process}

Tools like non-algorithm, tricks and techniques that are used to solve problem lead to heuristic problem solving approach. Investors determine the findings for themselves by the process of trial and error, which guides them to choose a certain opportunity. Investors' decision-making is not rational so it is very difficult to separate the emotional and mental factors involved in the process of decision-making in which the investors go through by collecting relevant evaluation of the information. Following factors are included in Heuristic Decision process:

- Representativeness: Kahneman \& Tversky (1972) describe representativeness heuristic that is used while making judgments regarding the probability of an event under the state of being unsure of something. Investors' tendency to make decisions established on previous experiences is known as stereotype. Kahneman \& Tversky (1982) first proposed it by defining representativeness as; (i) the level to which an event's characteristics are similar to its parent population, also (ii) contemplates prominent features of the procedure by which it is yielded.

- Overconfidence: Dittrich, Güth \& Maciejovsky, (2001) observed in their experiment that around two third of their participants prone to overconfidence. They further observed that those investors who lose their money in investment, gain more confidence. Confidence might have several dimensions, giving more courage, plays a vital role in gaining success. Confidence alone is not the sole factor to success but still it is usually celebrated and encouraged. Yet, self-confidence is always considered to be a positive trait. In certain cases, investors while overestimating their skills and knowledge indulge themselves into excessive trading.

- Anchoring: Human beings start estimating final results by initiating from the beginning values about different situations. That starting point or initial value may be the partial computation or the formulation of a problem. Adjustments are insufficient in both of the cases (Slovic \& Lichtenstein, 1971). Different initiating points come up with different estimates, which lead to initial values. This phenomenon is called 'anchoring' by Tversky \& Kahneman (1974).

- Gamblers Fallacy: While coming to probability, when lack of understanding leads to an incorrect estimation and prediction regarding the onset of events. That one incorrect assumption is called gambler's fallacy. This fallacy arises when the investors predict inappropriately and the anticipation may be good or poor.

- Availability bias: It occurs when the evidences that come to our mind are easily overweighed. This biasness causes overreaction by the investors to the market results whether they are positive or negative. Availability bias is a cognitive bias that drives to human to overestimate the probabilities of the events affiliated with memorable or vivid happenings. Investors aim excessive weight on the most information available while making decisions.

\section{Prospect Theory}

Kahneman and Tversky (1979) developed this theory. It is the theory which explains that people value their gains and losses differently. If two equal choices are given to an investor, one in terms of potential gains and the other one in terms of potential losses, the chances are that the investor would choose the former one. This theory is also called 'loss-aversion theory'. Key concepts of the theory as explained below:

- Framing: It is the first part of the prospect theory which leads to outcomes and contingencies associated to a particular problem. It is the way facts are presented which influences the choice of an investor. Kahneman \& Tversky (1979) found that unlike expected utility theory, investors mark gains and losses differently. Some even concluded that the investors generally conceive the loss of $\$ 1$ twice painful as compare to the pleasure of $\$ 1$ gain.

- Loss aversion: This is an important concept in psychology which receives a noticeable attention in analyzing the economic conditions. When an investor faces loss the he may become a riskseeker, but becomes a risk-averse while enjoying gains. Such phenomenon can be called loss 
aversion (Venkatesh, 2002). Schmidta \& Zankb (2002) discussing the loss aversion theory agrees to the views of (Kahneman \& Tversky, 1979).

- Regret aversion: This kind of aversion arises when an investor desires to avoid the pain of regret occurring from a bad investment decision. A cognitive phenomenon when people who believe in regret-aversion try to sufferings arising from these two types of mistakes. First one is the errors of commission and the second one is error of omission. The former happens when we choose misdirected actions and the latter happens when we forgo or overlook the opportunities.

- Mental Accounting: Thaler (1980) established this concept of Mental Accounting. Thaler, (1999) conceptualized that 'Mental Accounting Matters'. It is the tendency for people where they separate their accounts and classify them on the basis of variety of subjective criteria, showing the source of money and the intention of each account, and this determines the purchasing decision. It provides the way for decision makers to set the points of references for the accounts that determine losses or gains.

- Self-control: Investors are assumed to avoid the losses and shield their investments. According to the views of Thaler \& Shefrin (1981) investors should always show some sort of tolerance and should be looking for improving their self-control. Psychologically it is also known as selfregulation.

\section{Conclusion}

Much of the work has been done in the field of behavioral finance during the past decade. To construct a significant model of the behavior of investors in financial markets, the concepts are being merged from psychology, sociology and financial economics. Presently, no particular theory of behavioral finance exists. Shefrin \& Statman (1994) began their research work in this field, but as yet, more emphasis is being given to identify the attributes of behavioral decision-making, having systematic impacts on financial market behavior. Although behavioral finance does not claim that every investor would suffer from similar illusion, instead it sheds light on to take necessary initiatives to avoid such illusions which influence the process of decision-making, particularly while making investments.

\section{References}

Cyert, R. M. \& James, G. M. (1963). A Behavioural Theory of the Firm. Englewood Cliffs, NJ: Prentice-Hall.

Dittrich, D., Guth, W. \& Maciejovsky, B. (2005). Overconfidence in investment decisions: An experimental approach. European Journal of Finance, Taylor and Francis Journals, 11(6), 471-491.

Kahneman, D. \& Tversky, A. (1979). Prospect theory: An analysis of decision making under risk. Econometrica, 47(2), 263-291.

Kahneman, D. \& Tversky, A. (1982). The psychology of preferences. Scientific Ameri- can, 246, 160-73.

Lintner, G. (1998). Behavioural finance: Why investors make bad decisions. The Planner, 13(1), 7-8.

Margolis, J. (1958). The Analysis of the Firm: Rationalism, Conventionalism, and Behaviourism. Journal of Business, 31(3), 187-199.

Muneer, S. \& Rehman, U. S. (2012). Materialization of Behavioural Finance and Behavioural Portfolio Theory: A Brief Review. Journal of Economics and Behavioural Studies, 4(8), 431-435.

Olsen, R. (1998). Behavioural finance and its implications for stock price volatility. Financial Analysts Journal, 54(2), 10-18.

Ross, S. A., Westerfield, R. W. \& Jefferey, J. (2004). Corporate Finance. $7^{\text {th }}$ ed. New York, NY: McGrawHill/Irwin.

Schmidt, U. \& Zankb, H. (2002). What is Loss Aversion? available at http://lossaversion.behaviouralfinance.net/ScZa02.pdf

Shefrin, H. \& Meir, S. (1994). Behavioural Capital Asset Pricing Theory. Journal of Financial and Quantitative Analysis, 29(3), 323-349.

Simon, H. A. (1955). A behavioural model of rational choice. The Quarterly Journal of Economics, 69(1), 99118.

Simon, H. A. (1959). Theories of decision-making in economics and behavioural science. American Economic Review, 49, 253-283.

Slovic, P. (1972). Psychological study of human judgement: Implications for investment decision-making. Journal of Finance, 27, 779-801. 
Slovic, P. \& Lichtenstein, S. (1971). Comparison of Bayesian and regression approaches to the study of information processing in judgment. Organizational Behaviour and Human Performance, 6, 649744.

Thaler, R. J. (1999). Mental Accounting Matters. Journal of Behavioural Decision making, 12, 183-206.

Thaler, R. (1980). Toward a Positive Theory of Consumer Choice. Journal of Economic Behaviour and Organization, 1, 39-60.

Thaler, R. \& Shefrin, H. (1981). An economic theory of self-control. Journal of Political Economy, 89(2), 392-410.

Tversky, A. \& Kahneman, D. (1974). Judgement under uncertainty: Heuristics and biases. Science, 185, 1124-1131.

Venkatesh, B. (2002). What is Loss Aversion?' Business Line, Sunday, December -01. 